\title{
Structural and Transport Characteristics of Substituted Bismuth Niobates
}

\author{
O. S. Kaymieva, O. A. Tarasova, A. N. Shatokhina, E. S. Buyanova ${ }^{z}$, \\ M. V. Morozova, and V. M. Zhukovskii \\ Ural Federal University, ul. Mira 19, 620002 Ekaterinburg, Russia
}

Received July 3, 2012

\begin{abstract}
The results of studying solid solutions with the composition of $\mathrm{Bi}_{3} \mathrm{Nb}_{1-y} \mathrm{Zr}_{y} \mathrm{O}_{7 \pm \delta}$, $\mathrm{Bi}_{2.95} \mathrm{Y}_{0.05} \mathrm{Nb}_{1-y} \mathrm{Zr}_{y} \mathrm{O}_{7 \pm \delta}(y=0-0.5 ; \Delta y=0.1)$, and $\mathrm{Bi}_{6.95} \mathrm{Y}_{0.05} \mathrm{Nb}_{2-y} \mathrm{Zr}_{y} \mathrm{O}_{15.5}(y=0.1-1 ; \Delta y=0.1)$ are presented. XRD and electron microscopy with $\mathrm{X}$-ray microanalysis are used to determine the homogeneity regions of solid solutions; crystallochemical parameters are calculated. It is shown that irrespective of the ratio of $\mathrm{Bi}: \mathrm{Nb}$, two cubic phases are formed at an increase in the dopant amount. One of these represents a solid solution based on $\mathrm{Bi}_{3} \mathrm{NbO}_{7}$ ( $\delta$-phase) and the second one is a solid solution based on $\delta-\mathrm{Bi}_{2} \mathrm{O}_{3}\left(\delta^{\prime}\right.$-phase). Conductivity of sintered samples is studied using the impedance spectroscopy technique. Introduction of yttrium into the bismuth sublattice results in no increase in conductivity of solid solutions, while in the case of the ratio of $\mathrm{Bi}: \mathrm{Nb}=3: 1$, overall conductivity of solid solutions is somewhat higher at similar dopant concentrations.
\end{abstract}

Keywords: bismuth niobates, oxygen-ionic conductors, impedance spectroscopy

DOI: $10.1134 / \mathrm{S} 1023193513070057$

\section{INTRODUCTION}

The high-temperature modification of $\delta-\mathrm{Bi}_{2} \mathrm{O}_{3}$ is a solid electrolyte with high values of oxygen-ionic conductivity, but in a sufficiently narrow temperature range of $730-825^{\circ} \mathrm{C}$. The modification is crystallized in a fluorite structure with the oxygen sublattice population density of about $75 \%$ (the $F m 3 m$ space group). It can be stabilized at the room temperature by substitution of bismuth by various cations, such as $\mathrm{Nb}, \mathrm{Y}, \mathrm{Ta}$, rare earths [1-3]. In the system of $(1-x) \mathrm{Bi}_{2} \mathrm{O}_{3}: x \mathrm{Nb}_{2} \mathrm{O}_{5}$ [4], variation of the content of $\mathrm{Nb}_{2} \mathrm{O}_{5}$ results in formation of four different structure types: cubic structure (type I, $x<0.06$ ); pseudocubic structure with different values of all three lattice parameters (type II, $0.06<x<0.23$ ) [5]; tetragonal phase (type III, $\mathrm{Bi}_{3} \mathrm{NbO}_{7}$ ) existing at the temperatures between 800 and $900^{\circ} \mathrm{C}$ [6]. Type IV is represented by the compound of $\mathrm{Bi}_{5} \mathrm{Nb}_{3} \mathrm{O}_{15}$ that is closer to a perovskite-type structure than to the $\mathrm{CaF}_{2}$ structure [7].

Bismuth niobate $\mathrm{Bi}_{3} \mathrm{NbO}_{7}$, according to [8], is an oxygen-ionic conductor; its conductivity is $5 \times$ $10^{-4} \mathrm{~S} / \mathrm{cm}$ at $600^{\circ} \mathrm{C}$. Niobate $\mathrm{Bi}_{7} \mathrm{Nb}_{2} \mathrm{O}_{15.5}$, according to [9], has a significant electronic conductivity at low temperatures $\left(\leq 600^{\circ} \mathrm{C}\right)$. Doping by yttrium or an increase in the ratio of $\mathrm{Bi}: \mathrm{Nb}$ in niobates result in a decrease in the contribution of electronic conductivity. In the case of samples of the $\mathrm{Bi}_{7} \mathrm{Nb}_{2-x} \mathrm{Y}_{2 x} \mathrm{O}_{15.5-x}$ $(0.0 \leq x \leq 0.1)$ system with high yttrium content, a

\footnotetext{
${ }^{z}$ Corresponding author: Elena.Buyanova@usu.ru (E.S. Buyanova).
}

transition into the region with a lower activation energy is observed at high temperatures [10]. The authors explain this by the temperature dependence of oxygen distribution across the $8 \mathrm{c}$ and $32 \mathrm{f}$ sites of the crystalline structure. $8 \mathrm{c}$ sites with the coordinates of $(0.25,0.25,0.25)$ correspond to an ideal fluorite structure and $32 \mathrm{fc}$ sites have the coordinates of $(0.3,0.3,0.3)$. Oxygen ions in $32 \mathrm{f}$ sites are in the migration path between $8 \mathrm{c}$ and are characterized by higher mobility. For compounds with a high population density of $32 \mathrm{f}$ sites, a lower activation energy and lower contribution of electronic conductivity are observed. Besides, a decrease in activation energy is favored by substitution of $\mathrm{Nb}^{5+}$ by a cation with a lower charge, which results in a decrease in the dopant-vacancy interaction and an increase in the amount of vacancies. Studies of the $\mathrm{Bi}_{3} \mathrm{Nb}_{1-x} \mathrm{Zr}_{x} \mathrm{O}_{7 \pm \delta}(0.0 \leq x \leq 1.0)$ solid solutions revealed appearance of a cubic phase characterized by larger lattice parameters at an increase in the dopant concentration in the $\delta^{\prime}$-modification [11]. The $\delta$-phase is characterized by long-range ordering, while the $\delta^{\prime}$-phase is ordered locally. This results in the fact that the structure of the $\delta^{\prime}$-phase is most suitable for movement of $\mathrm{O}^{2-}$ ions.

There is a region of solid solutions based on the high-temperature $\delta$-phase of $\mathrm{Bi}_{2} \mathrm{O}_{3}$ in the system of bismuth oxide-yttrium oxide $[12,13]$. In the case of doping of more than $25 \%$ of yttrium, temperature dependences of conductivity are linear [13]. However, in the case of samples with a lower yttrium content, a 
jump corresponding to a phase transition and a significant hysteresis (about $50-100^{\circ}$ ) between the heating and cooling cycles are observed. In [14], the character of disordering in $\left(\mathrm{Bi}_{2} \mathrm{O}_{3}\right)_{1-x}\left(\mathrm{Y}_{2} \mathrm{O}_{3}\right)_{x}$ solid solutions is explained by the electron structure of $\mathrm{Bi}^{3+}$ and $\mathrm{Y}^{3+}: \mathrm{Y}^{3+}$ has a closed shell and $\mathrm{Bi}^{3+}$ has a free electron pair, due to which $\mathrm{Y}^{3+}$ is characterized by a constant coordination environment and the environment of $\mathrm{Bi}^{3+}$ can vary. The authors believe that introduction of $\mathrm{Y}_{2} \mathrm{O}_{3}$ into $\mathrm{Bi}_{2} \mathrm{O}_{3}$ results in formation in the solid solution of microdomains with the $\mathrm{Y}_{2} \mathrm{O}_{3}$-like anion environment, which leads to a decrease in the amount of defects in $\delta-\mathrm{Bi}_{2} \mathrm{O}_{3}$ and its stabilization.

Thus, isovalent substitution of bismuth by yttrium in bismuth niobate can promote stabilization of a fluorite-type modification, while heterovalent substitution in the niobium sublattice can lead to an increase in the concentration of oxygen vacancies.

The aim of the present work is to obtain and analyze the structure and electrochemical characteristics of solid solutions with the following compositions: $\mathrm{Bi}_{3} \mathrm{Nb}_{1-y} \mathrm{Zr}_{y} \mathrm{O}_{7 \pm \delta}, \mathrm{Bi}_{2.95} \mathrm{Y}_{0.05} \mathrm{Nb}_{1-y} \mathrm{Zr}_{y} \mathrm{O}_{7 \pm \delta}(y=0-0.5$; $\Delta y=0.1)$, and $\mathrm{Bi}_{6.95} \mathrm{Y}_{0.05} \mathrm{Nb}_{2-y} \mathrm{Zr}_{y} \mathrm{O}_{15.5}(y=0.1-1$; $\Delta y=0.1)$.

\section{EXPERIMENTAL}

Solid solutions with the composition of $\mathrm{Bi}_{3} \mathrm{Nb}_{1-y} \mathrm{Zr}_{y} \mathrm{O}_{7 \pm \delta}, \mathrm{Bi}_{2.95} \mathrm{Y}_{0.05} \mathrm{Nb}_{1-y} \mathrm{Zr}_{y} \mathrm{O}_{7 \pm \delta}(y=0-0.5$; $\Delta y=0.1)$, and $\mathrm{Bi}_{6.95} \mathrm{Y}_{0.05} \mathrm{Nb}_{2-y} \mathrm{Zr}_{y} \mathrm{O}_{15.5}(y=0.1-1$; $\Delta y=0.1$ ) were synthesized according to the standard ceramic technique in the temperature range of 873$1123 \mathrm{~K}$ with the step of $50 \mathrm{~K}$. The initial components used were bismuth oxides $\mathrm{Bi}_{2} \mathrm{O}_{3}$ (extra pure grade), niobium oxide $\mathrm{Nb}_{2} \mathrm{O}_{5}$ (extra pure grade), yttrium oxide $\mathrm{Y}_{2} \mathrm{O}_{3}$ (extra pure grade), zirconium oxide $\mathrm{ZrO}_{2}$ (analytical grade). The initial substances were presintered in a furnace at the temperatures of $873 \mathrm{~K}$ and $1273 \mathrm{~K}$ to remove water and obtain stable modifications. Intermediate milling was carried out in an agate mortar using ethanol as a homogenizer. The conditioning time at each stage was $8 \mathrm{~h}$.

The phase composition of the final products was controlled using the XRD technique. Analysis was carried out using a DRON-3 diffractometer. X-ray patterns were measured in $\mathrm{Cu} K_{\alpha}$ radiation in the angle range of $2 \theta=20-60 \mathrm{grad}$ at the rate of $2 \mathrm{grad} / \mathrm{min}$. Precision X-ray studies using a DRON-UM1 diffractometer $\left(\mathrm{Cu} K_{\alpha}\right.$ radiation, a monochromator of pyrolytic graphite in a reflected beam). Silicon with the elementary cell lattice of $a=5.43094(2) \AA$ was used as the external standard. The following software packages were used for calculation of unit cell parameters and specification of the crystalline structure: "FPeaK", "Celref", FullProf [15]. Surface morphology and the local chemical composition of sintered briquets were studied using electron microscopy (a JEOL JSM 6390LA raster electron microscope). The bulk density was determined using the hydrostatic

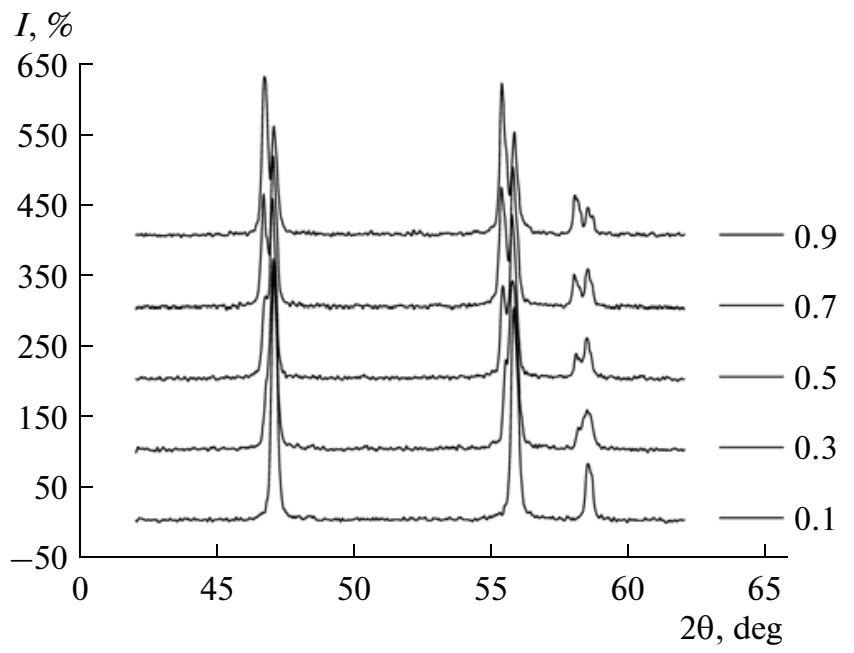

Fig. 1. Change in the $X$-ray pattern of $\mathrm{Bi}_{6.95} \mathrm{Y}_{0.05} \mathrm{Nb}_{2-y} \mathrm{Zr}_{y} \mathrm{O}_{15.5 \pm \delta}$ as dependent on the composition.

weighing technique. Conductivity of samples was studied using the impedance spectroscopy technique (an Elins Z-3000 impedance meter) in the temperature range of $1073-573 \mathrm{~K}$.

\section{RESULTS AND DISCUSSION}

The XRD data allowed establishing the limits of the homogeneity regions of solid solutions with the composition of $\mathrm{Bi}_{3} \mathrm{Nb}_{1-y} \mathrm{Zr}_{y} \mathrm{O}_{7 \pm \delta}, \mathrm{Bi}_{2.95} \mathrm{Y}_{0.05} \mathrm{Nb}_{1-y} \mathrm{Zr}_{y} \mathrm{O}_{7 \pm \delta}$ $(y=0-0.5 ; \Delta y=0.1)$, and $\mathrm{Bi}_{6.95} \mathrm{Y}_{0.05} \mathrm{Nb}_{2-y} \mathrm{Zr}_{y} \mathrm{O}_{15.5}$ $(y=0.1-1 ; \Delta y=0.1)$ were synthesized according to the standard ceramic technique. The homogeneity region of $\mathrm{Bi}_{2.95} \mathrm{Y}_{0.05} \mathrm{Nb}_{1-y} \mathrm{Zr}_{y} \mathrm{O}_{7 \pm \delta}$ is limited by the value of $y \leq 0.3$. An increase in the dopant concentration results in appearance of reflexes of the second cubic phase with the largest lattice parameter in $\mathrm{X}$-ray patterns. In the case of the series of $\mathrm{Bi}_{6.95} \mathrm{Y}_{0.05} \mathrm{Nb}_{2-y} \mathrm{Zr}_{y} \mathrm{O}_{15.5 \pm \delta}$, appearance of the second cubic phase (by analogy with [11], let us designate it as the $\delta^{\prime}$-phase) with the largest crystal lattice parameter is observed already at $y=0.3$, while at $y \geq 0.7$, this cubic phase prevails over the primary one (let us designate is as the $\delta$-phase). Both phases are crystallized in a cubic fluorite structure (the $F m 3 m$ space group). An example of variation of the $\mathrm{X}$-ray pattern at an increase in the dopant content for $\mathrm{Bi}_{6.95} \mathrm{Y}_{0.05} \mathrm{Nb}_{2-{ }_{y}} \mathrm{Zr}_{y} \mathrm{O}_{15.5 \pm \delta}$ is shown in Fig. 1. For yttrium-free $\mathrm{Bi}_{3} \mathrm{Nb}_{1-y} \mathrm{Zr}_{y} \mathrm{O}_{7 \pm \delta}$ formulations, appearance of the second phase at an increase in the concentration of zirconium is observed at $x=0.4$. Appearance of the second cubic phase is related by some authors $[16,17]$ to structural rearrangements of oxygen ions within a cubic lattice. It is emphasized herewith that the chemical composition remains unchanged. But the authors of [18] argue against homogeneity of the chemical composition for $\mathrm{Bi}_{3} \mathrm{Nb}_{1-y} \mathrm{Zr}_{y} \mathrm{O}_{7 \pm \delta}$; it is assumed that zirconium is not embedded into the sec- 


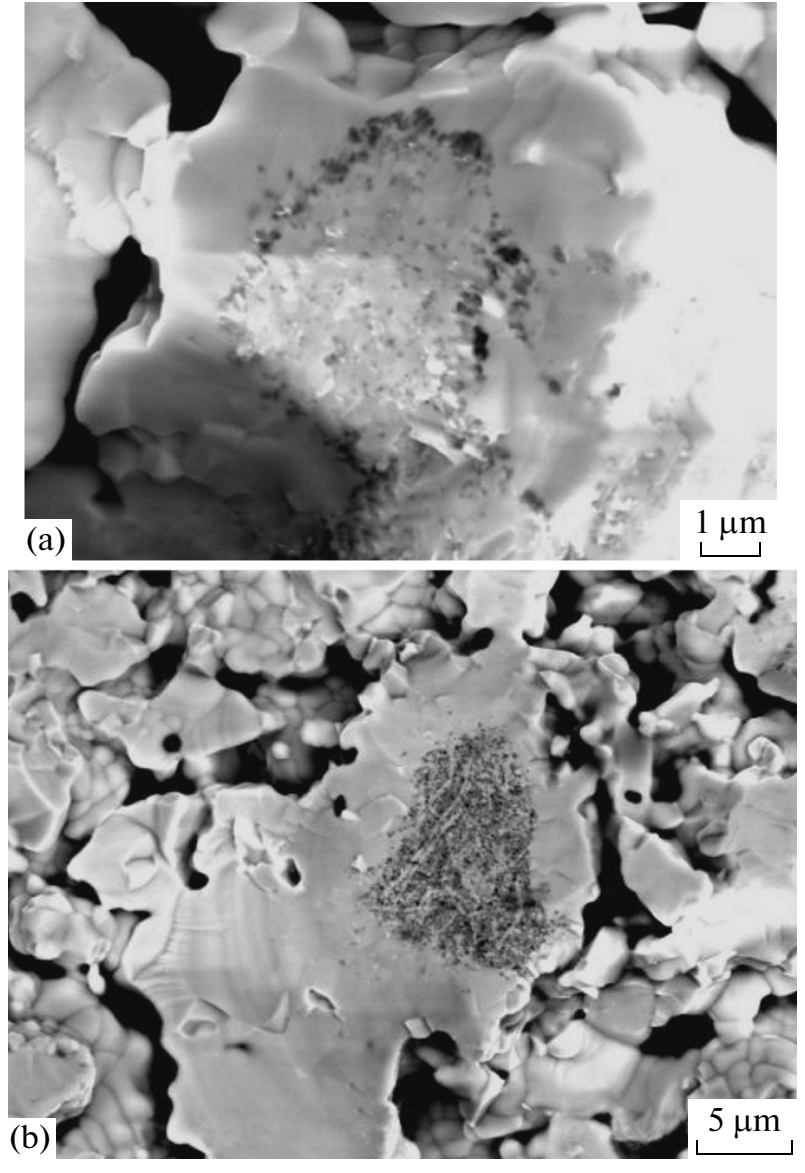

Fig. 2. Microimages of a section of sintered briquets: (a) $\mathrm{Bi}_{2.95} \mathrm{Y}_{0.05} \mathrm{Nb}_{0.8} \mathrm{Zr}_{0.2} \mathrm{O}_{7 \pm \delta}$;

$\mathrm{Bi}_{6.95} \mathrm{Y}_{0.05} \mathrm{Nb}_{1.4} \mathrm{Zr}_{0.6} \mathrm{O}_{15.5 \pm \delta}$.

ond cubic phase and remains in the form of a $\mathrm{ZrO}_{2}$ impurity. The appearing peaks are attributed to $\mathrm{Bi}_{1.78} \mathrm{Nb}_{0.22} \mathrm{O}_{3.22}$.

To identify the composition of the second phase, electron microscopy and precision X-ray studies of some formulations were carried out. Elementary lattice parameters were specified at the example of $\mathrm{Bi}_{6.95} \mathrm{Y}_{0.05} \mathrm{Nb}_{1.4} \mathrm{Zr}_{0.6} \mathrm{O}_{15.5 \pm \delta}$. According to the data of $\mathrm{XRD}$, the $\mathrm{Bi}_{6.95} \mathrm{Y}_{0.05} \mathrm{Nb}_{1.4} \mathrm{Zr}_{0.6} \mathrm{O}_{15.5 \pm \delta}$ sample represents a mixture of two phases: presumably, two solid solutions based on $\mathrm{Bi}_{0.75} \mathrm{Nb}_{0.25} \mathrm{O}_{1.75}$; in other words, $\mathrm{Bi}_{3} \mathrm{NbO}_{7}$ (the $F m 3 m$ space group, $a=5.465 \AA$ ) with different content of yttrium and zirconium.

As follows from the XRD data, the $\mathrm{Y}^{3+}, \mathrm{Zr}^{4+}$, and $\mathrm{Nb}^{5+}$ cations are indistinguishable; therefore, the initial assumptions regarding the composition of these phases were based on analysis of the elementary lattice parameters: $a_{1}=5.4660(1) \AA$ ( $\delta$-phase $), a_{2}=$ $5.4980(1) \AA$ ( $\delta^{\prime}$-phase). As follows from the ratio of ionic radii of cation in similar environment, $r_{\mathrm{Nb}^{5+}}(0.64 \AA)<r_{\mathrm{Zr}^{4+}}(0.72 \AA)<r_{\mathrm{Y}}(0.90 \AA)$ [19], and proximity of parameters of the $\delta$-phase and $\mathrm{Bi}_{0.75} \mathrm{Nb}_{0.25} \mathrm{O}_{1.75}$, it was assumed that the $\delta$ phase was niobium-enriched, while the $\delta^{\prime}$-phase contains both niobium and zirconium. The data were refined for the $\mathrm{Fm} 3 m$ space group, in which the $\mathrm{Bi}, \mathrm{Y} / \mathrm{Zr} / \mathrm{Nb}$ atoms occupy the $4 \mathrm{a}(0,0,0)$ sites, while oxygen occupies the $32 \mathrm{f}(0.3,0.3,0.3)$ and $48 \mathrm{i}(0.5,0.2,0.2)$ sites [17]. The results of specification do not contradict the above assumptions, but energy-dispersive microanalysis was carried out to provide an accurate answer to the question regarding the phase composition.

The results of $\mathrm{X}$-ray microanalysis of the $\mathrm{Bi}_{6.95} \mathrm{Y}_{0.05} \mathrm{Nb}_{1.4} \mathrm{Zr}_{0.6} \mathrm{O}_{15.5 \pm \delta}$ tablet surface were used to establish inhomogeneity of the chemical composition. A negligible saturation of one of the phases by bismuth and of the other by niobium was observed. Yttrium content in this case is beyond the sensitivity of the technique. Porous inclusions of negligible size were found in the section of the tablet (Fig. 2b). The chemical composition of the inclusion differs considerably from the composition of the main phase regarding the amount of zirconium, but the content of this phase is low. As follows from the data of microanalysis, the $\delta$-phase is a solid solution based on $\mathrm{Bi}_{0.75} \mathrm{Nb}_{0.25} \mathrm{O}_{1.75}$, i.e., $\mathrm{Bi}_{3} \mathrm{Nb}_{0.72} \mathrm{Zr}_{0.28} \mathrm{O}_{7-\delta}$. The $\delta^{\prime}$-phase, $\mathrm{Bi}_{1.7} \mathrm{Nb}_{0.23} \mathrm{Zr}_{0.07} \mathrm{O}_{3.30-\delta}$, is enriched by bismuth, which explains an increase in its amount in the sample at an increase in the dopant concentration (the ratio of $\mathrm{Bi}: \mathrm{Nb}$ increases).

The results of studies for a sample with the composition of $\mathrm{Bi}_{2.95} \mathrm{Y}_{0.05} \mathrm{Nb}_{0.8} \mathrm{Zr}_{0.2} \mathrm{O}_{7 \pm \delta}$ are shown in Fig. 2a. In this case, the phase with high zirconium content ( $\delta$-phase) is also found in the sample. The ratio of metallic atoms in it is $\mathrm{Bi}: \mathrm{Nb}: \mathrm{Zr}=3: 0.7: 0.2$. For the second phase ( $\delta^{\prime}$-phase), the ratio is $\mathrm{Bi}: \mathrm{Nb}=$ $1.2: 0.3$, i.e., it is also bismuth-rich. As the $\mathrm{Bi}_{2.95} \mathrm{Y}_{0.05} \mathrm{Nb}_{0.8} \mathrm{Zr}_{0.2} \mathrm{O}_{7 \pm \delta}$ sample contains a single phase according to the XRD data, in this case, the amount of this phase is negligible. Thus, for all the studied series of solid solutions, irrespective of the ratio of $\mathrm{Bi}: \mathrm{Nb}$, two cubic phases are formed at an increase in the dopant amount. One of these represents a solid solution based on $\mathrm{Bi}_{3} \mathrm{NbO}_{7}(\delta$-phase) and the second one is a solid solution based on $\delta-\mathrm{Bi}_{2} \mathrm{O}_{3}$ $\left(\delta^{\prime}\right.$-phase). X-ray characteristics of the phases are shown in Tables 1 and 2.

Solid solution powders were compacted and sintered into briquets to study conductivity. To estimate the briquette sintering density, bulk density and overall porosity of ceramics were assessed. Porosity of the ceramics did not exceed 5\% practically for all samples.

Conductivity of solid solutions was studied using the impedance spectroscopy technique in the cooling mode in the temperature range of $1073-573 \mathrm{~K}$. Measurements were carried out using a two-probe method with platinum electrodes. Typical impedance complexplane plots at the example of a $\mathrm{Bi}_{2.9} \mathrm{Y}_{0.1} \mathrm{Nb}_{0.6} \mathrm{Zr}_{0.4} \mathrm{O}_{7 \pm \delta}$ sample are shown for different temperatures in Fig. 3. As seen from the figures, the shape of the dependence varies at a change in the temperature. Under cooling, the complex-plane plot assumes the shape of a semicircle consisting of two semicircles. Equivalent circuits 
Table 1. Crystallographic characteristics of solid solutions

\begin{tabular}{c|c|c|c|c|c|c|c|c}
\hline \multirow{2}{*}{$\begin{array}{c}\text { Compo- } \\
\text { sition, } x\end{array}$} & \multicolumn{3}{|c|}{$\mathrm{Bi}_{6.95} \mathrm{Y}_{0.05} \mathrm{Nb}_{2-y} \mathrm{Zr}_{y} \mathrm{O}_{15.5 \pm \delta}$} & \multicolumn{3}{c}{$\mathrm{Bi}_{2.95} \mathrm{Y}_{0.05} \mathrm{Nb}_{1-y} \mathrm{Zr}_{y} \mathrm{O}_{7 \pm \delta}$} \\
\cline { 2 - 9 } & $a \pm 0.006, \AA$ & $V \pm 0.4, \AA^{3}$ & $a \pm 0.006, \AA$ & $V \pm 0.4, \AA^{3}$ & $a \pm 0.003, \AA$ & $V \pm 0.08, \AA^{3}$ & $a \pm 0.003, \AA$ & $V \pm 0.08, \AA^{3}$ \\
\hline 0.1 & 5.459 & 162.7 & - & - & 5.462 & 162.92 & & \\
0.2 & 5.460 & 162.7 & - & - & 5.463 & 163.06 & & \\
0.3 & 5.462 & 163.0 & 5.488 & 165.3 & 5.461 & 162.88 & & \\
0.4 & 5.467 & 163.4 & 5.496 & 166.0 & 5.458 & 162.63 & 5.490 & 165.50 \\
0.5 & 5.466 & 163.3 & 5.499 & 166.3 & 5.456 & 162.41 & 5.493 & 165.76 \\
\hline
\end{tabular}

Table 2. Crystallographic characteristics of $\mathrm{Bi}_{3} \mathrm{Nb}_{1-y} \mathrm{Zr}_{y} \mathrm{O}_{7 \pm \delta}$ solid solutions

\begin{tabular}{c|c|c|c|c|c}
\hline \multirow{2}{*}{ Composition } & \multirow{2}{*}{$y$} & \multicolumn{2}{|c|}{$\delta$} & \multicolumn{2}{c}{$\delta^{\prime}$} \\
\cline { 3 - 6 } & & $a \pm 0.003, \AA$ & $V \pm 0.08, \AA^{3}$ & $a \pm 0.003, \AA$ & $V \pm 0.08, \AA^{3}$ \\
\hline & 0.1 & 5.461 & 162.91 & - & - \\
$\mathrm{Bi}_{3} \mathrm{Nb}_{1-y} \mathrm{Zr}_{y} \mathrm{O}_{7 \pm \delta}$ & 0.2 & 5.465 & 163.20 & - & - \\
& 0.3 & 5.461 & 162.91 & - & 167.06 \\
& 0.4 & 5.465 & 163.21 & 5.508 & 166.84 \\
\hline
\end{tabular}

of cells corresponding to occurrence of processes in a given temperature range were chosen using the Zview software (Version 2.6b, Scribner Associates, Inc.). The obtained shape of the dependence at $723 \mathrm{~K}$ can be described by an equivalent circuit consisting of serially connected resistances $R_{1}$ and $R_{2}$ with constant phase elements CPE1 and CPE2 connected in parallel to them. Overall conductivity of a polycrystalline sample at low temperatures was calculated on the basis of the sum of $R_{1}+R_{2}$. The left semicircles are degenerated at an increase in the temperature, while a distorted semicircle appears that probably corresponds to the electrode processes. The distorted semicircle is probably a combination of at least two semicircles corresponding in the equivalent circuit to the combination of resistances $R_{3}$ and $R_{2}$ with constant phase elements CPE2 and CPE1. At high temperatures, the sum of bulk and grain boundary resistances corresponds to resistance $R_{1}$ that was used to calculate overall conductivity of the sample. Due to the narrow temperature range in which the grain boundary component can be distinguished, bulk conductivity was not separated to the bulk and grain boundary components.

The results of impedance measurements were used to plot the temperature dependences of overall conductivity. The obtained data are presented in the form of plots of the temperature dependence of conductivity in the Arrhenius coordinates and tables with electrophysical characteristics (Figs. 4-6, Table 3). The general run of temperature dependences of conductivity for the studied solid solutions has the shape typical for the cubic modification of bismuth niobate [8-10]. Two linear regions can be distinguished in the dependences. The transition between them is accompanied by a slight change in the conductivity activation energy. For $\mathrm{Bi}_{3} \mathrm{Nb}_{1-y} \mathrm{Zr}_{y} \mathrm{O}_{7 \pm \delta}(y \leq 0.5), \mathrm{Bi}_{2.95} \mathrm{Y}_{0.05} \mathrm{Nb}_{1-y} \mathrm{Zr}_{y} \mathrm{O}_{7 \pm \delta}$ $(y \leq 0.1)$, and $\mathrm{Bi}_{6.95} \mathrm{Y}_{0.05} \mathrm{Nb}_{2-y} \mathrm{Zr}_{y} \mathrm{O}_{15.5 \pm \delta}(y \leq 0.5)$, the high-temperature region corresponds to higher activation energy values than at lower temperatures (Table 3 ). By analogy with the results of [9], one can suggest that
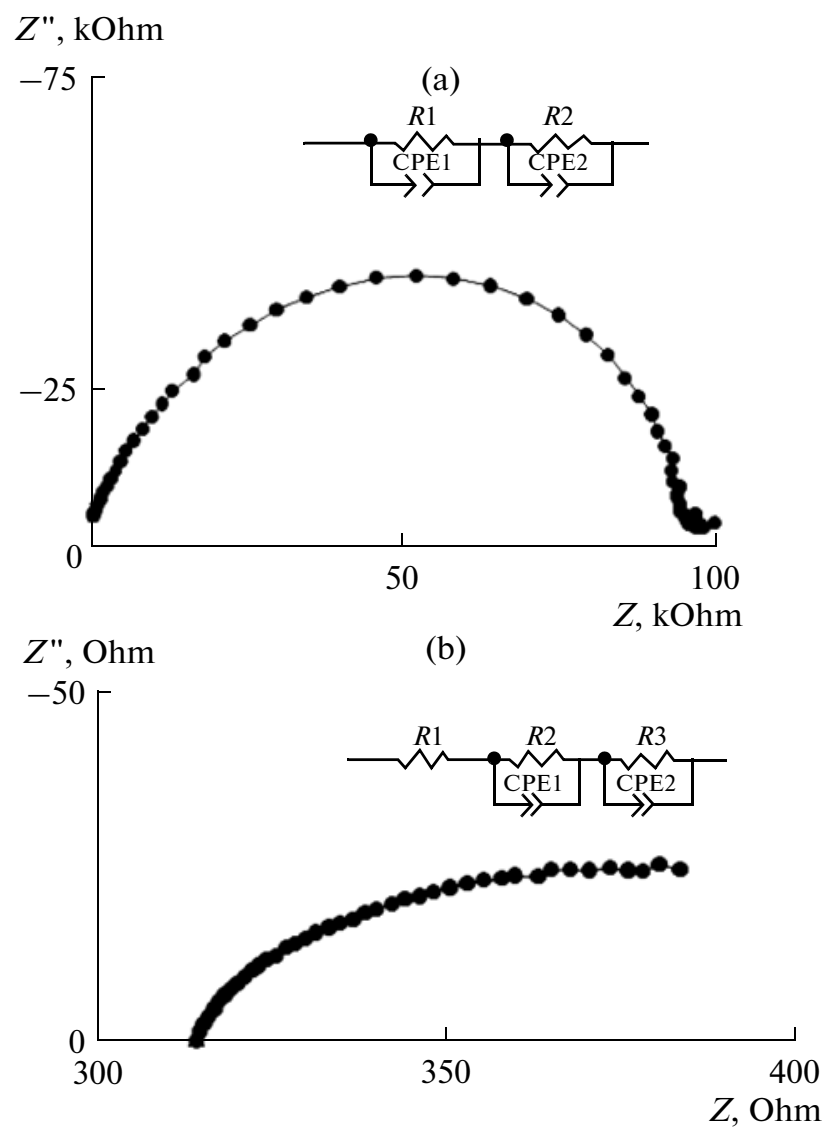

Fig. 3. Impedance complex-plane plots of a sample with the composition of $\mathrm{Bi}_{2.9} \mathrm{Y}_{0.1} \mathrm{Nb}_{0.6} \mathrm{Zr}_{0.4} \mathrm{O}_{6.8}$ : (a) at $723 \mathrm{~K}$, (b) at $1058 \mathrm{~K}$; and the corresponding equivalent circuits. 


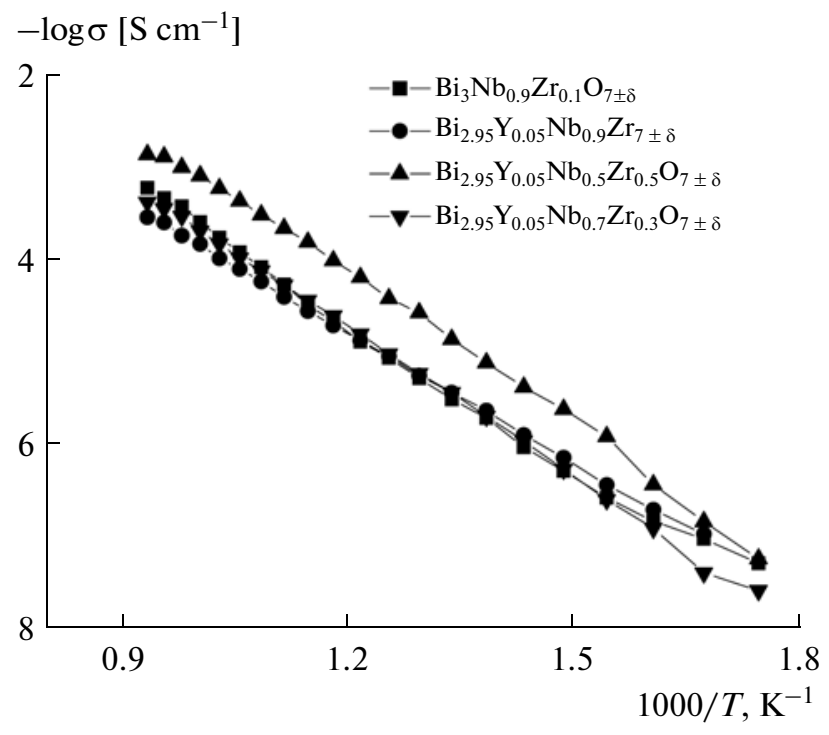

Fig. 4. Temperature dependences of conductivity of $\mathrm{Bi}_{2.95} \mathrm{Y}_{0.05} \mathrm{Nb}_{1-y} \mathrm{Zr}_{y} \mathrm{O}_{7 \pm \delta}$ solid solutions.

this is related to transition from electronic conductivity to ionic conductivity (study of the contribution of electronic conductivity into overall conductivity of the studied samples is planned at a later stage). However, the situation is changed to the opposite at an increase in the amount of the dopant in the case of $\mathrm{Bi}_{2.95} \mathrm{Y}_{0.05} \mathrm{Nb}_{1-y} \mathrm{Zr}_{y} \mathrm{O}_{7 \pm \delta}$. A transition into the region with lower activation energy is observed for samples with $y \geq 0.2$ at high temperatures, which is possibly due to the temperature dependence of oxygen distribution across the $8 \mathrm{c}$ and $32 \mathrm{f}$ sites of the crystalline structure [10]. As follows from Fig. 4b, conductivity of the studied systems changes negligibly at an increase in the concentration of zirconium in the region of solid solution homogeneity. In the case when the second cubic phase forms a solid solution based on $\delta-\mathrm{Bi}_{2} \mathrm{O}_{3}$ (the $\delta$-phase) at an increase in the $y$ value, being, as pointed out above, conductivity of samples increases

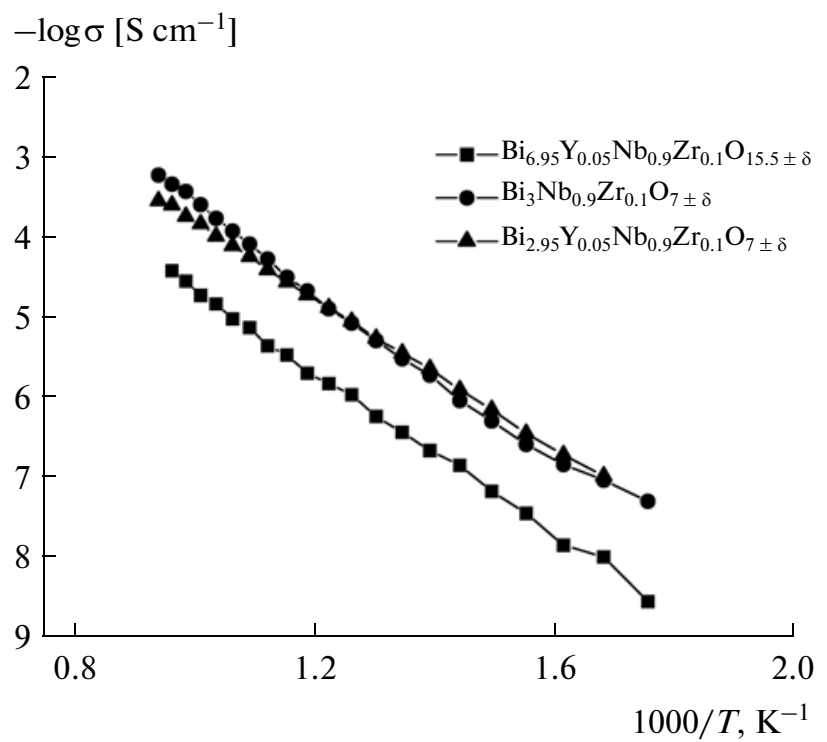

Fig. 5. Temperature dependences of conductivity of solid solutions with a different ratio of $\mathrm{Bi}: \mathrm{Nb}$ and a similar concentration of zirconium $(y=0.1)$.

considerably, as the $\delta$-modification of bismuth oxide in itself is highly conducting by oxygen ions.

Comparison of the formulations of $\mathrm{Bi}_{3} \mathrm{Nb}_{1-y} \mathrm{Zr}_{y} \mathrm{O}_{7 \pm \delta}, \quad \mathrm{Bi}_{2.95} \mathrm{Y}_{0.05} \mathrm{Nb}_{1-y} \mathrm{Zr}_{y} \mathrm{O}_{7 \pm \delta}$, and $\mathrm{Bi}_{6.95} \mathrm{Y}_{0.05} \mathrm{Nb}_{2-y} \mathrm{Zr}_{y} \mathrm{O}_{15.5 \pm \delta}$ (Figs. 5 and 6) allows pointing out that addition of yttrium into the bismuth sublattice does not result in an increase in the solid solution conductivity, while in the case of the ratio of $\mathrm{Bi}: \mathrm{Nb}=3: 1$, overall conductivity of solid solutions is somewhat higher at similar dopant concentrations.

Thus, this work shows the possibility of formation of solid solutions with substitution in both lattices, $\mathrm{Bi}_{2.95} \mathrm{Y}_{0.05} \mathrm{Nb}_{1-y} \mathrm{Zr}_{y} \mathrm{O}_{7 \pm \delta}$ and $\mathrm{Bi}_{6.95} \mathrm{Y}_{0.05} \mathrm{Nb}_{2-y} \mathrm{Zr}_{y} \mathrm{O}_{15.5}$, at low dopant concentrations, with crystallization in a cubic fluorite structure (the Fm $3 m$ space group). However, such an approach results in no significant improvement in conducting characteristics of bismuth niobates. An increase in the dopant content leads to formation of the second cubic phase ( $\delta^{\prime}$-phase) based

Table 3. Electrophysical characteristics of solid solutions

\begin{tabular}{c|c|c|c|c}
\hline \multirow{2}{*}{ Composition } & $y$ & \multirow{2}{*}{$\begin{array}{c}E_{\text {act }}, \mathrm{eV} \\
T>720 \mathrm{~K}\end{array}$} & $\begin{array}{c}E_{\text {act }}, \mathrm{eV} \\
T<720 \mathrm{~K}\end{array}$ & $\sigma, \mathrm{S} \mathrm{cm}^{-1}$ \\
\cline { 3 - 5 } & & 1.21 & 0.91 & $T=873 \mathrm{~K}$ \\
\hline $\mathrm{Bi}_{3} \mathrm{Nb}_{1-y} \mathrm{Zr}_{y} \mathrm{O}_{7 \pm \delta}$ & 0.1 & 0.98 & 0.94 & $3.4 \times 10^{-5}$ \\
\hline $\mathrm{Bi}_{2.95} \mathrm{Y}_{0.05} \mathrm{Nb}_{1-y} \mathrm{Zr}_{y} \mathrm{O}_{7 \pm \delta}$ & 0.1 & 1.05 & 1.16 & $2.9 \times 10^{-5}$ \\
& 0.3 & 1.02 & 1.20 & $3.7 \times 10^{-5}$ \\
& 0.5 & 1.12 & 1.05 & $1.7 \times 10^{-4}$ \\
\hline $\mathrm{Bi}_{6.95} \mathrm{Y}_{0.05} \mathrm{Nb}_{2-y} \mathrm{Zr}_{y} \mathrm{O}_{15.5 \pm \delta}$ & 0.1 & 1.06 & 0.97 & $3.5 \times 10^{-6}$ \\
& 0.3 & 1.11 & 0.95 & $3.4 \times 10^{-5}$ \\
& 0.5 & & $5.5 \times 10^{-5}$ \\
\hline
\end{tabular}




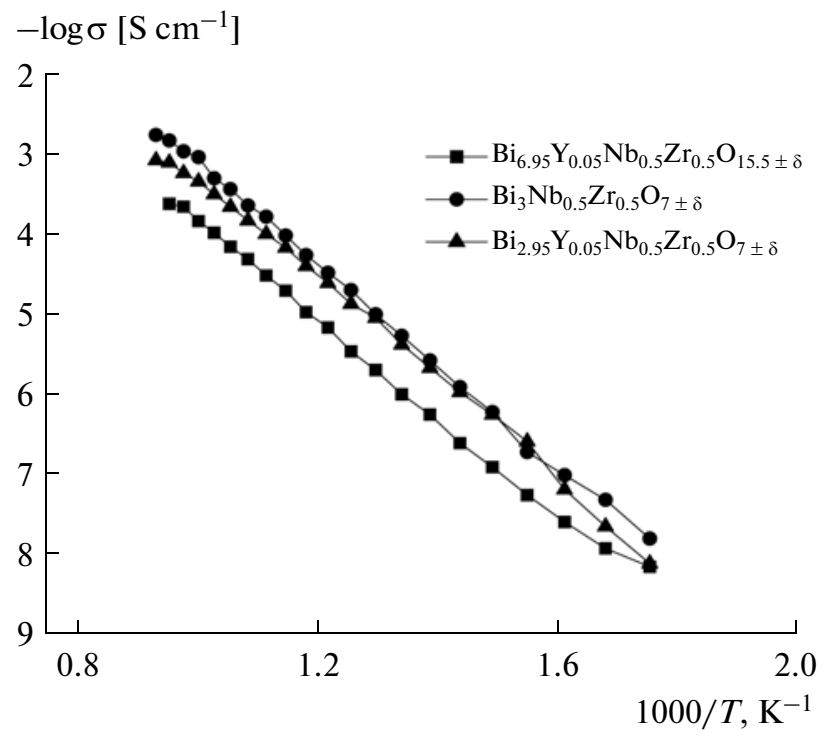

Fig. 6. Temperature dependences of conductivity of solid solutions with a different ratio of $\mathrm{Bi}: \mathrm{Nb}$ and a similar concentration of zirconium $(y=0.5)$.

on bismuth oxide with a much higher conductivity, which results in enhancement of overall system conductivity.

This study was financially supported by the Russian Foundation for Basic Research, grants no. 12-0331119 and the Ministry of education and science of Russian Federation, projects no. 14.A18.21.1186, 14.132.21.1455.

\section{REFERENCES}

1. Ling, C.D., J. Solid State Chem., 2004, vol. 177, p. 1838.

2. Watanabe, A., Solid State Ionics, 1994, vol. 79, p. 84.
3. Castro, A., Mater. Res. Bull., 1998, vol. 33, no. 1, p. 31.

4. Roth, R.S. and Waring, J.L., J. Res. Natl. Bur. Stand., Sect. A, 1962, vol. 66A, no. 6, p. 451.

5. Withers, R.L., Ling, C.D., and Schmid, S., Z. Kristallogr., 1999, vol. 214, p. 296.

6. Wang, X.P., J. Solid State Chem., 2006, vol. 179, p. 3338.

7. Ling, C.D., J. Solid State Chem., 1999, vol. 148, no. 11, p. 380 .

8. Borowska-Centkowska, A., Solid State Ionics, 2010, vol. 181, p. 1750.

9. Malys, M., Holdynski, M., Krok, F., Wrobel, W., Dygas, J.R., Pirovano, C., and Abrahams, I., J. Power Sources, 2009, vol. 194, p. 16.

10. Krok, F., Abrahams, I., Holdynski, M., KozaneckaSzmigiel, A., Malys, M., Struzic, M., Liu, X., and Dygas, J.R., Solid State Ionics, 2008, vol. 179, p. 975.

11. Krok, F. and Abrahams, I., Solid State Ionics, 2004, vol. 175 , p. 335 .

12. Watanabe, A. and Kikuchi, T., Solid State Ionics, 1986, vol. 21 , no. 4, p. 287.

13. Takahashi, T., Iwahara, H., and Arao, T., J. Appl. Electrochem., 1975, vol. 5, p. 95.

14. Battle, P.P., Gattow, G., and Heap, J.W., J. Solid State Chem., 1989, vol. 61, p. 8.

15. Rodriguez-Carvajal, J., Physica B, 1993, vol. 192, p. 55.

16. Abrahams, I., Wrobel, W., Chan, S.C.M., Kozanecka, A., Krok, F., and Dygas, J.R., Solid State Ionics, 2006, vol. 179, p. 1761.

17. Abrahams, I., Krok, F., Chan, S.C.M., Wrobel, W., Kozanecka-Scmigiel, A., Luma, A., and Dygas, J.R., J. Solid State Electrochem., 2006, vol. 10, p. 569.

18. Abrahams, I., Krok, F., Wrobel, W., KozaneckaSzmigiel, A., and Chan, S.C.M., Solid State Ionics, 2008, vol. 179, p. 2.

19. Shannon, R.D., Acta Crystallogr., 1976, vol. 32, p. 751.

Translated by M. Ehrenburg 